\title{
Fürchtet Euch nicht!
}

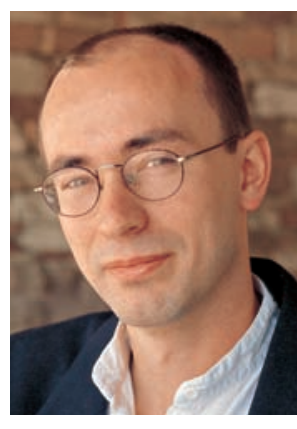

Dr. med. Dieter Schmid, Redaktionsleitung
[1] A. Prehn-Kristensen et al. Induction of Empathy by the Smell of Anxiety. Pub. Lib. of Sci. ONE 2009; doi:

10.1371/journal.pone.0005987
Nein, in dieser Via medici geht es nicht um die Schweinegrippe. Der junge Mann auf dem Titel weitet seine Augen nicht so panisch wegen einer drohenden Virusinfektion. Topthema dieses Heftes ist die Prüfungsangst! Diese quälende Missempfindung ist ebenfalls hochansteckend - und sie riecht. Und zwar buchstäblich. Forscher aus Kiel haben das vor kurzem in einer Studie herausgefunden, in der sie 49 Prüflingen kurz vor einem Examen Wattepads in die Achselhöhlen steckten. Zudem mussten die Probanden Schweißproben nach sportlicher Betätigung abliefern. Diese Geruchsproben hielten die Wissenschaftler 28 Testpersonen vor, die parallel mit funktioneller MRT untersucht wurden. Ergebnis: Die Angst-Proben aktivierten bei den Untersuchten, anders als die Sport-Proben, Gehirnareale, die auf die Wahrnehmung von Angstgefühlen und empathischem Miterleben spezialisiert sind [1]. Mit anderen Worten: Allein die Ausdünstungen eines Prüfungsangstgeplagten reichen bereits aus, um bei Kommilitonen ähnliche Gefühle entstehen zu lassen. Lesen Sie deshalb unseren Artikel „Begeistert bis zum Kollaps“ (S. 8). Wir geben Tipps, wie Sie Examenspanik kurieren können - und so Lerngruppengefährten vor „Ansteckung“ schützen.

Zum Glück hat Prüfungsangst die prima Eigenschaft, dass sie sich nach dem Examen von einer Stunde auf die andere in Luft auflöst. Andere Angststörungen wie Panikattacken, Phobien und die Posttraumatische Belastungsstörung (PTBS) sind da hartnäckiger. PTBS-Patienten leiden noch Jahrzehnte nach einem schlimmen Erlebnis unter Albträumen und „Flashbacks“. Hauptschuld trägt - wie bei den meisten Angststörungen - eine Übererregung des Mandelkerns. Dieses kleine Areal im limbischen System analysiert Gefahren und löst Angst aus, wenn es eine Situation als gefährlich erkennt. In unserem Artikel „Trauma in der Endlosschleife“ auf S. 34 erklären wir Ihnen, warum der Mandelkern bei der PTBS in einem Teufelskreis festsitzt und warum das Hormon Cortisol dabei helfen könnte, diesen aufzubrechen.

In Deutschland leiden 7 Millionen Menschen an chronischen Angststörungen - oftmals unerkannt und untherapiert. Sofern die Angst ein vernünftiges Maß nicht übersteigt, hat sie aber auch ihr Gutes: Sie schützt zum Beispiel vor Gefahren und kann - gerade vor Prüfungen - extrem motivationsfördernd wirken. Wird die Angst vor dem Versagen - trotz aller guten Tipps - vor einem Examen allzu quälend, kann vielleicht folgende Weisheit des US-Sängers Bob Dylan zur Entspannung beitragen. „There's no success like failure“, singt er in seinem Song „Love Minus Zero“. Frei übersetzt: „Es gibt kein schöneres Erfolgserlebnis, als einmal auf die Nase zu fallen.“

In der Hoffnung, dass Ihnen dieser Gedanke zwar nutzt, Ihnen dieses „Erfolgserlebnis“ aber erspart bleiben möge:

$\mathrm{Ihr}$

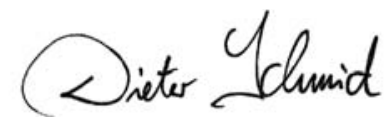

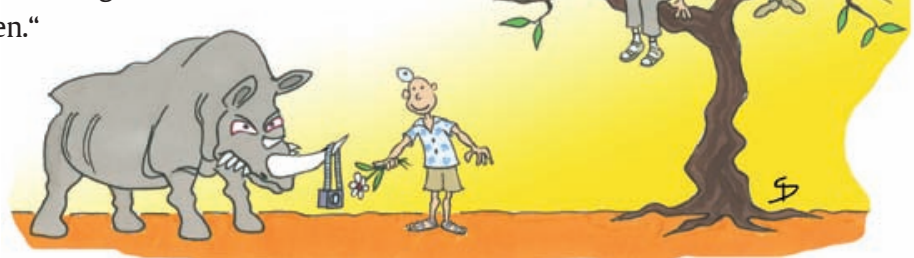

„Angst? Nein, er hat vor drei Wochen das Physikum geschafft.“ 